\title{
NOTES
}

\section{Glass-Like Transition of Poly(p-toluenesulfonyl L-lysine)}

\author{
Shintaro SASAKI and Ichitaro UEMATSU \\ Department of Polymer Chemistry, Tokyo Institute of Technology, \\ Ookayama, Meguro-ku, Tokyo 152, Japan
}

(Received March 15, 1983)

\begin{abstract}
KEY WORDS Polypeptides / $\alpha$-Helix / Glass-Like Transition / X-Ray
Diffraction / Circular Dichroism /
\end{abstract}

In a previous paper, ${ }^{1}$ we analyzed the crystal structure of poly( $p$-toluenesulfonyl L-lysine) (PTLL) [(-NHCHRCO- $)_{n}, \quad \mathrm{R}=-\left(\mathrm{CH}_{2}\right)_{4} \mathrm{NHSO}_{2}-$ $\mathrm{C}_{6} \mathrm{H}_{4} \mathrm{CH}_{3}$ ]. The main chain takes on a righthanded $\alpha$-helical conformation. In the crystalline phase (hexagonal unit cell with dimensions $a=$ $1.680 \mathrm{~nm}$ and unit height $h=0.1498 \mathrm{~nm}$ ), the $p$ toluenesulfonyl groups are located at intermediate positions between neighboring helices, and thus intervene with one another. In this paper, we discuss the effect of the structural characteristics on the glass-like transition of PTLL films, which so far has been attributed to the onset of side-chain motion.

A sample of PTLL was synthesized using the previously outlined procedure. ${ }^{1}$ Its intrinsic viscosity in dichloroacetic acid at $25^{\circ} \mathrm{C}$ was $0.28 \mathrm{dl} \mathrm{g}^{-1}$, which corresponds to that of poly $(\gamma$-benzyl L- glutamate) with a molecular weight of 38,000 in the same solvent. ${ }^{2}$ Solid films were prepared by casting chloroform solutions of the sample.

Infrared spectra were measured at room temperature for the as-cast film (I) and the film (II) annealed at $150^{\circ} \mathrm{C}$ for $1 \mathrm{~h}$. The spectra of the two films were exactly the same and characteristic of the $\alpha$-helical conformation, and unchanged up to $150^{\circ} \mathrm{C}$.

The density was measured for (I) and (II) at $25^{\circ} \mathrm{C}$ by the floatation method using an aqueous $\mathrm{KBr}$ solution and also a mixture of carbon tetrachloride and cyclohexane. The measured values were $1.318 \mathrm{~g}$ $\mathrm{cm}^{-3}$ for (I) and $1.285 \mathrm{~g} \mathrm{~cm}^{-3}$ for (II). The calculated density of the crystal is $1.280 \mathrm{~g} \mathrm{~cm}^{-3} .^{1}$ It should be noted that the as-cast film is much denser than the annealed film.

Figure 1 shows the X-ray diffraction patterns of (I) and (II) at room temperature. The main-chain

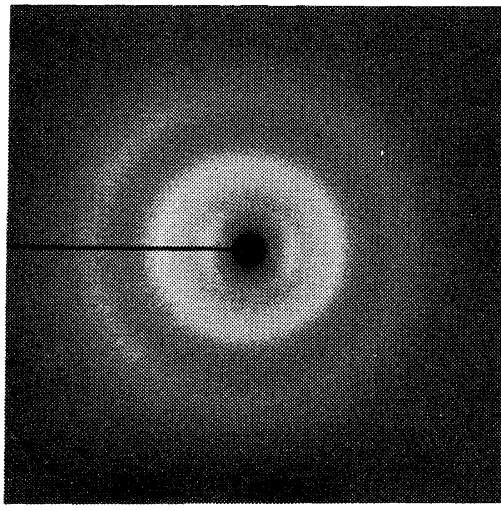

(a)

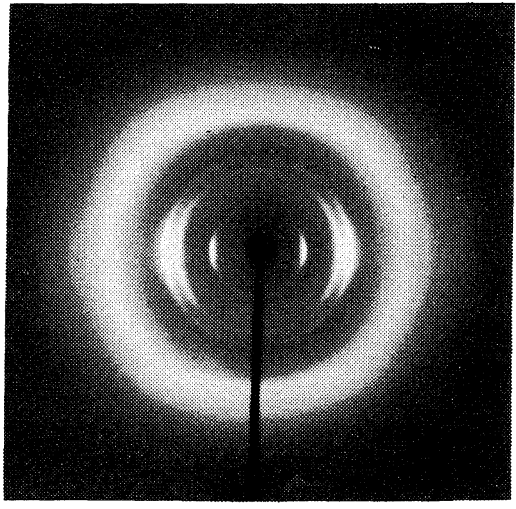

(b)

Figure 1. X-Ray diffraction photographs of (a) as-cast and (b) annealed films of PTLL. 


\section{S. SASAKI and I. UEMATSU}

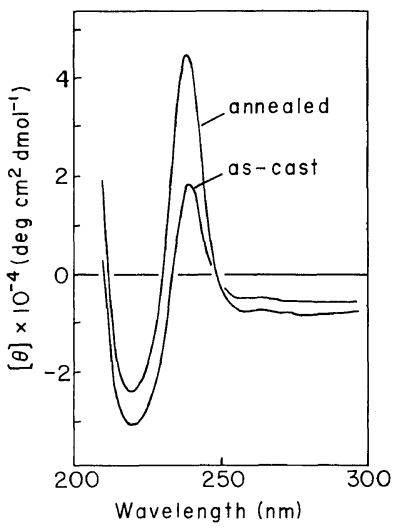

Figure 2. Circular dichroism of PTLL films.

helices in the annealed film are regularly arranged in the hexagonal net. ${ }^{1}$ As inferred from the broad pattern, the structure of (I) is less ordered, at least, in regard to the main-chain arrangement.

Films of polypeptides do not, in general, display the circular dichroism (CD) associated with sidechain chromophores, since the side chains are intrinsically achiral and rather disordered even in the crystalline phase. Figure 2 shows the CD spectra of (I) and (II) recorded at room temperature. The specimen was prepared by casting dilute solutions onto a quartz plate, and the thickness was determined from the infrared absorbance of the amide $\mathrm{A}$ band at $3288 \mathrm{~cm}^{-1}$. The effect of birefringence due to molecular orientation was negligible. The positive $\mathrm{CD}$ band at $238 \mathrm{~nm}$ was ascribed to the $\pi-\pi^{*}$ transition of helically-arranged $p$ toluenesulfonamide chromophores (absorption maximum: $229 \mathrm{~nm}) .{ }^{1}$ This extrinsic $\mathrm{CD}$ band partly overlaps with the negative band at $222 \mathrm{~nm}$ associated with the $n-\pi^{*}$ transition of the main-chain peptide groups. The broad negative trough around $270 \mathrm{~nm}$ may have been induced by another absorption of the $p$-toluenesulfonamide group at $263 \mathrm{~nm} .{ }^{3}$ The intensity of the band at $238 \mathrm{~nm}$ doubled by annealing.

These results indicate that the arrangement of the main chains and the side chains becomes more ordered by annealing. The difference in the structures of (I) and (II) may affect their physical properties. It is well known that polypeptides having long side chains exhibit a glass-like transition associated with side-chain motion. The as-cast film (I) of PTLL was soft at room temperature, while the

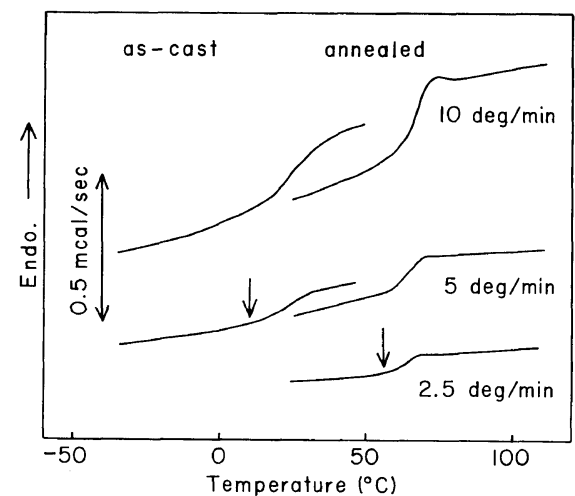

Figure 3. Differential scanning calorimetric thermograms of PTLL film $(20 \mathrm{mg})$ recorded at a heating rates of 10,5 , and $2.5 \mathrm{deg} \mathrm{min}^{-1}$.

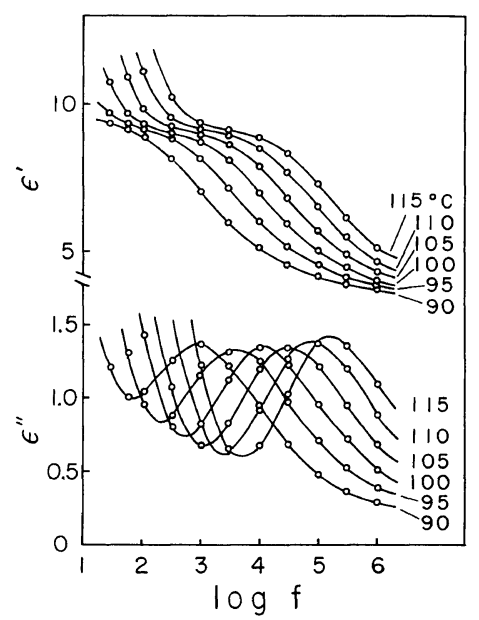

Figure 4. Frequency dependence of the dielectric constant $\varepsilon^{\prime}$ and loss factor $\varepsilon^{\prime \prime}$ measured for an annealed film of PTLL.

annealed film (II) was brittle. Thermal behavior typical of a glass transition was observed for these films, as shown in Figure 3. The transition was assumed to take place at the temperatures indicated by arrows. The transition temperature of (I), about $10^{\circ} \mathrm{C}$, is comparable with those of polypeptides having similar side chains, for instance, $8^{\circ} \mathrm{C}$ for poly( $\varepsilon$-carbobenzoxy L-lysine) ${ }^{4}$ Film (II) showed a transition at a much higher temperature (about $\left.56^{\circ} \mathrm{C}\right)$.

As has already been reported, the intensity of the 238-nm CD band of the film (II) remained constant below $55^{\circ} \mathrm{C}$ and decreased gradually at higher tem- 
peratures. ${ }^{1}$ Its temperature dependence was reversible in the heating and cooling cycles. A break point suggesting a glass-like transition was also observed for the temperature dependence of the dc conductivity of PTLL films, ${ }^{5}$ as has been reported for various polymers. ${ }^{6}$

The dielectric dispersion due to the side-chain motion was measured for the annealed film (II). Figure 4 shows the frequency dependence of the dielectric constant $\varepsilon^{\prime}$ and the loss factor $\varepsilon^{\prime \prime}$. The measurements were carried out in an electrode system with a guard ring using conductive silver paste. The relationship between relaxation time and temperature was accurately described by the "universal" Williams-Landel-Ferry equation with a reference temperature of $105^{\circ} \mathrm{C}\left(50^{\circ} \mathrm{C}\right.$ above the glass-like transition).

The side chains in the crystalline phase of PTLL intervene in the region between the neighboring helices. ${ }^{1}$ The bulky side chains may be responsible for the regular arrangement about the main-chain helix. Judging from the glass-like transition temperatures, the side chains in the disordered phase (in the as-cast film) may not intervene in the region between the neighboring helices, although some degree of chiral arrangement of the side chains can be inferred from the CD spectra. It is interesting that the as-cast film is denser but exhibits a glasslike transition at a temperature lower than the annealed film.

\section{REFERENCES}

1. S. Sasaki, S. Shinohara, and I. Uematsu, Polym. Bull., 9, 437 (1983).

2. P. Doty, J. H. Bradbury, and A. M. Holtzer, J. Am. Chem. Soc., 78, 947 (1956).

3. L. Doub and J. M. Vandenbelt, J. Am. Chem. Soc., 69, 2714 (1947).

4. K. Hikichi, A. Tsutsumi, S. Isozaki, and M. Kaneko, Polym. J., 7, 646 (1975).

5. S. Sasaki and I. Uematsu, unpublished data.

6. S. Hirota, Polym. J., 14, 583 (1982). 